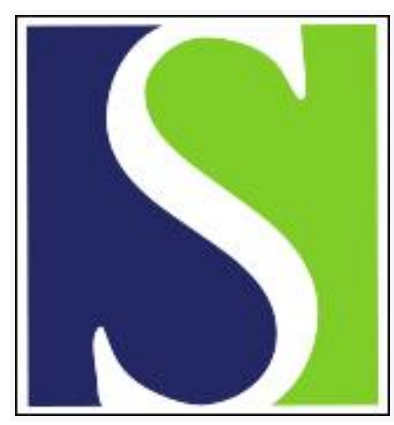

Scand J Work Environ Health 2005;31(1):65-74

https://doi.org/10.5271/sjweh.850

Issue date: Feb 2005

Assessment of exposure to wheat flour and the shape of its relationship with specific sensitization

by Peretz C, de Pater N, de Monchy J, Oostenbrink J, Heederik D

Affiliation: Institute for Risk Assessment Sciences, University of Utrecht, PO Box 80176, Utrecht, The Netherlands. c.peretz@iras.uu.nl

Key terms: atopy; baker; exposure; exposure-response; model; occupational exposure; sensitization; variance component; wheat flour

This article in PubMed: www.ncbi.nlm.nih.gov/pubmed/15751621

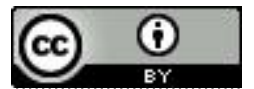




\title{
Assessment of exposure to wheat flour and the shape of its relationship with specific sensitization
}

\author{
by Chava Peretz, PhD, ${ }^{1,2}$ Nettie de Pater, MSc, ${ }^{1,3}$ Jan de Monchy, MD, ${ }^{4}$ Joke Oostenbrink, MD, ${ }^{4}$ Dick \\ Heederik, $P h D^{1}$
}

Peretz C, de Pater N, de Monchy J, Oostenbrink J, Heederik D. Assessment of exposure to wheat flour and the shape of its relationship with specific sensitization. Scand J Work Environ Health 2005;31(1):65-74.

\begin{abstract}
Objectives Dust and wheat-allergen exposure were assessed among bakers, flour millers, and bakeryingredient producers, and the risk for sensitization was studied.

Methods About 520 inhalable dust and wheat-allergen measurements were made among 270 Dutch workers. Data on sensitization to wheat and common allergens (atopy) were also available. Exposure was estimated according to the sector of industry, job title, and tasks. The shape of the relationship between sensitization and exposure was studied using a two-stage modeling approach: semi-parametric generalized additive modeling and, consequently, a simple description of the relationship using a parametric logistic model. To reduce the effect of exposure measurement errors (attenuation), a combination of the actual measured exposure and variance-weighted estimates of exposure was used.

Results The effect of exposure to both inhalable dust and wheat allergens on sensitization was described best by a linear relationship in three industries and a quadratic relationship in one industry. The relation for the whole study population was best described as quadratic, and the probability of sensitization increased with exposure up to $\sim 2.7 \mathrm{mg} / \mathrm{m}^{3}$ for inhalable dust and $\sim 25.7 \mu \mathrm{g} \mathrm{EQ} / \mathrm{m}^{3}$ for wheat allergens. The risk decreased at higher exposures $(\mathrm{P}=0.0121$ and $\mathrm{P}=0.0731$ for dust and wheat, respectively). Atopy and sector of industry modified the sensitization risk significantly in all the analyses. Using a variant-weighted estimator to calculate exposures corrected for the bias and resulted in almost the same point risk estimators.

Conclusions Exposure-response relationships for allergens may be nonlinear and differ between industries. A threshold is not indicated on which to base occupational exposure standards; alternatively, other approaches, such as benchmarking, seem warranted.
\end{abstract}

Key terms atopy; bakers; exposure-response; models; occupational exposure; variance components.

Interest in risk assessment for allergens has been growing in several countries and professional bodies [eg, the American Conference of Governmental Industrial Hygienists, (ACGIH) $(1,2)$ and the Dutch Expert Committee for Occupational Standards (DECOS) (3)]. On the basis of these risk assessments, health-based exposure standards have been proposed for diminishing the risk of sensitization to wheat flour allergens. Such proposals were made by both ACGIH and DECOS (1-3). Other organizations, such as the Health and Safety Executive (HSE) in the United Kingdom and the Nordic Expert
Group, favored a different approach, for which the rationale has been described earlier $(4,5)$. The standard-setting process is complicated because only a few studies have dealt in any detail with exposure among bakers and sensitization, mainly because such data were not available until recently (6-9). Moreover, the shape of the relationship has not been studied in depth in most earlier studies. Instead, it has either been based on simple categorization of the exposure or on job titles (eg, bread versus cake bakers) or assumed to be linear. Risk assessments have, as a result, been fairly simple and

Institute for Risk Assessment Sciences, Department of Occupational and Environmental Health, University of Utrecht, Utrecht, The Netherlands.

2 School of Health Professions, Sackler Faculty of Medicine, Tel Aviv University, Tel Aviv, Israel.

3 The Netherlands Organization for Applied Scientific Research (TNO), Zeist, The Netherlands.

4 University Groningen, Department of Allergology, Groningen, The Netherlands.

Correspondence to: Professor Dick Heederik, Institute for Risk Assessment Sciences, University of Utrecht, PO Box 80176, Utrecht, The Netherlands. [E-mail: d.heederik@iras.uu.nl] 
straightforward and based on a subjective or intuitive interpretation of the data. The shape of the exposureresponse relationships for sensitization agents has received specific attention in more recent studies of the indoor environment, and the results were suggestive of a bell-shaped curve for some allergens and a linear curve for others (10). This study is therefore based on new data collected for an occupational allergen in four sectors of industry and, thereby, includes workers with higher levels of exposure to both inhalable dust and wheat flour than in earlier studies. Earlier analyses of this data set ignored the fact that task information can be used and that it allows more powerful modeling approaches to be used. Advanced exposure modeling is necessary to obtain a refined assessment of exposure estimates that allows subsequent evaluation of the derived exposure-response shape.

Therefore, in this paper, exposure-determinant modeling was carried out to evaluate estimated exposure levels of inhalable dust and wheat allergens on the basis of measurements among occupational wheat-exposed populations. In addition, for risk assessment purposes, a refined nonlinear exposure-sensitization relationship was explored with advanced statistical tools.

\section{Study population and methods}

\section{Study population}

The data originated from a survey among Dutch bakers including a medical part and a hygiene part, carried out between August 2000 and July 2001. We limited our study to 270 workers who were included in both the hygiene and medical surveys in 83 companies. The following four sectors of industry were studied: traditional bakeries, industrialized bakeries, flour mills, and the bakery-ingredient industry.

\section{Occupational factors}

The occupational factors studied included industry sector, job title within a sector, and tasks performed within a job title, referred to as exposure determinants. Each sector comprised several jobs. [See appendix I for details.] About 30 jobs within the sectors were observed. In addition, about 80 tasks were distinguished. Most of the tasks involved short-term peak exposures to dust (eg, emptying bags, weighing, cleaning), and because these tasks were performed in different sectors and with different technology, 80 were distinguished. Overall, 108 combinations of industrial sector, job title, and task were considered. This number is considerably less than the maximal number of combinations because of the nested structure of the data.

\section{Dust and allergen exposure measurement}

Personal inhalable dust samples were collected in the worker's breathing zone during full-shift periods of $6-$ 8 hours using PAS6 sampling heads (TNO, Delft, The Netherlands) at a flow rate of $21 / \mathrm{min}$. Dust levels (milligrams per cubic meter) were measured by weighing in a preconditioned weighing room before and after the measurements. Wheat allergens were recovered from the filters by extraction using a buffer solution (phosphate buffered saline), and the wheat-allergen concentrations were measured in the extract by inhibition immunoassay, using a pool of human immunoglobulin (Ig) $\mathrm{G}_{4}$ polyclonal antibodies, as described earlier and expressed in the microgram equivalent per cubic meter $\left(\mu \mathrm{g} E Q / \mathrm{m}^{3}\right)(7)$. For the 270 workers, 335 personal inhalable dust samples were collected, and, of these, 298 wheat-allergen exposure measurements were made.

\section{Repeated exposure measurements}

Of the 270 bakers, 208 (77\%) had one exposure measurement, 59 (22\%) had two repeated measurements, and $3(1 \%)$ had three repeated measurements. The measurements were repeated within a 2 - to 6 -week period with randomly selected workers from the four sectors. We repeated the measurements so that we could make an additional assessment of the day-to-day variability of exposure in a subset of workers.

\section{Health outcomes}

Wheat-specific sensitization. Venous blood samples were analyzed for the presence of specific IgE antibodies against wheat-flour allergens using the Pharmaca Diagnostics Uni CAP assay. Workers with levels of class 1 or higher were considered positive.

Atopy. Sera were also analyzed for the presence of $\operatorname{IgE}$ against common allergens such as house dust mite and grasses. The workers were considered atopic if any of the common allergens had a level of class 1 or higher.

\section{Statistical analyses}

The statistical analyses were performed using SAS software $(11,12)$. Exposure values below the detection limit were replaced by two-thirds of this limit. Some extremely high exposure levels were replaced by the 98th percentile (ie, $100 \mathrm{mg} / \mathrm{m}^{3}$ for inhalable dust and $400 \mu \mathrm{g} \mathrm{EQ} /$ $\mathrm{m}^{3}$ for the wheat-allergen level. The exposure distributions for both inhalable dust and wheat allergens were found to be log-normal (7), and, therefore, natural logtransformation was used in the statistical analysis. 
Exposure assessment. Linear mixed effects models, which account for the correlation between the repeated measurements, were used for estimating (SAS-proc mixed) the exposure to inhalable dust and wheat allergens. All the models had a log exposure level as the dependent variable. We included sector of industry, job title, and 80 tasks as covariates to identify tasks associated with exposure. Only the tasks with at least borderline statistical significance $(\mathrm{P} \leq 0.10)$ on the level of either inhalable dust or wheat-allergen exposure were included in the additional analysis. Variance components between and within workers were estimated. Simpler models were analyzed (ignoring task, only industry and job title included), but they have not been presented because they were clearly suboptimal.

The following three exposure assessment approaches were considered: (i) measured exposure for each individual worker, (ii) estimated exposure based on the aforementioned model (which accounts for sector of industry, job title, and tasks performed), and (iii) a combination of the previous two approaches, referred to as the variance-weighted estimator of exposure, based on measured and estimated exposure. (See appendix II.) The variance-weighted estimator is a modification of the approach proposed by Seixas \& Sheppard (13), in which estimated exposure and actual measurements are combined, with weights based on the variance between and within workers. It reduces negative effects of grouping strategies (described in relation to Berkson error).

Modeling exposure-response relationships. The relationship between sensitization (no, yes) and exposure to inhalable dust and wheat allergens was first evaluated by calculating the sensitization prevalence among categories of exposure, sector of industry, and atopic status (SAS-proc freq/univariate).

To explore the shape of the relationship between sensitization and exposure, we fit a semi-parametric generalized additive model for each industry and the whole population and adjusted for the following parametric effects: atopy (no, yes) and sector of industry (4 categories) as the linear predictors of the parametric part of the model and log concentration as an additive predictor as the nonparametric part of the model. The term for the additive predictor was fit using a spline as a smoother (14). The model is a generalized model since the probability distribution of the dependent variable sensitization (binary: no, yes) is binomial and the relationship with the predictors is through a nonlinear link function $[\operatorname{logit}=\mathrm{p} /(1-\mathrm{p})]$. The degrees of freedom for the additive predictor were selected with the use of a generalized cross-validation method that indicates the degree of the polynomial that represents the data (SAS-proc GAM). We used scatter plots (not shown) to present the relationship of the logged concentration and the smothed dust and wheat exposure.

After inspecting the semi-parametric curve and interpreting the cross-validation parameter that is given by the generalized additive model analysis, we chose a parametric model - a generalized linear model (with distribution $=$ binomial and link $=$ logit), in which the dependent variable was the logit of sensitization and the independent variables were atopy, sector of industry, and linear and quadratic terms of the logged concentration. Odds ratios and confidence limits of exposure, atopic status, and sector of industry were estimated for sensitization with this logistic model (SAS-proc genmod). The goodness-of-fit of the model was evaluated according to the deviance. The semi-parametric model and the parametric model were applied with the three different exposure assessment approaches, measured exposure, estimated exposure based on sector of industry, job title and tasks performed (three covariates), and a variance-weighted estimator of measured and estimated exposure.

\section{Results}

\section{Exposure assessment}

Table 1 presents the summary statistics for the measured exposure within the various sectors, ignoring the dependence between repeated measures. The highest mean exposure level, for both inhalable dust and wheat allergens, was observed for the flour mills (geometric means:

Table 1. Summary statistics of exposure to inhalable dust and to wheat allergens within sectors. $[\mathrm{GM}=$ geometric mean, GSD = geometric standard deviation, EQ = equivalent (in comparison with an arbitrary wheat allergen mixture standard)].

\begin{tabular}{|c|c|c|c|c|c|c|c|}
\hline \multirow[t]{2}{*}{ Sector } & \multirow[t]{2}{*}{ Workers (N) } & \multicolumn{3}{|c|}{ Inhalable dust $\left(\mathrm{mg} / \mathrm{m}^{3}\right)$} & \multicolumn{3}{|c|}{ Wheat allergens $\left(\mu \mathrm{g} E Q / \mathrm{m}^{3}\right)$} \\
\hline & & Measurements (N) & GM & GSD & Measurements (N) & GM & GSD \\
\hline Traditional bakeries & 70 & 80 & 1.71 & 2.99 & 65 & 8.63 & 7.45 \\
\hline Industrialized bakeries & 72 & 91 & 1.03 & 3.72 & 83 & 2.14 & 14.07 \\
\hline Flour mills & 73 & 94 & 2.72 & 4.07 & 85 & 9.41 & 9.32 \\
\hline Bakery-ingredient industry & 55 & 70 & 1.16 & 4.42 & 65 & 2.66 & 11.03 \\
\hline Total & 270 & 335 & 1.56 & 3.98 & 298 & 4.64 & 11.38 \\
\hline
\end{tabular}


Table 2. Variance components and $95 \%$ confidence intervals $(95 \% \mathrm{Cl})$ of exposure a to inhalable in dust $\left(\mathrm{mg} / \mathrm{m}^{3}\right)$ and to wheat allergens $\left(\mu \mathrm{gEQ} / \mathrm{m}^{3}\right)$. [EQ = equivalent (in comparison with an arbitrary wheat allergen mixture standard)]

\begin{tabular}{|c|c|c|c|c|c|c|c|c|c|c|}
\hline \multirow{2}{*}{$\begin{array}{l}\text { Exposure } \\
\text { determinants }\end{array}$} & \multicolumn{5}{|c|}{ Dust } & \multicolumn{5}{|c|}{ Wheat allergens } \\
\hline & $\begin{array}{l}\text { Between- } \\
\text { worker } \\
\text { variance }\end{array}$ & $95 \% \mathrm{Cl}$ & $\begin{array}{l}\text { Within- } \\
\text { worker } \\
\text { variance }^{b}\end{array}$ & $95 \% \mathrm{Cl}$ & $\begin{array}{l}\text { Reduction of } \\
\text { between- } \\
\text { worker } \\
\text { variance }\end{array}$ & $\begin{array}{l}\text { Between- } \\
\text { worker } \\
\text { variance }\end{array}$ & $95 \% \mathrm{Cl}$ & $\begin{array}{l}\text { Within- } \\
\text { worker } \\
\text { variance }^{b}\end{array}$ & $95 \% \mathrm{Cl}$ & $\begin{array}{c}\text { Reduction of } \\
\text { between- } \\
\text { worker } \\
\text { variance }\end{array}$ \\
\hline None & 1.16 & $0.86-1.64$ & 0.74 & $0.54-1.07$ & 0 & 4.00 & $3.03-5.51$ & 1.88 & $1.30-2.96$ & 0 \\
\hline Sector+ job + task & 0.25 & $0.10-1.57$ & 0.78 & $0.55-1.20$ & $78^{c}$ & 1.75 & $1.08-3.31$ & 1.62 & $1.06-2.79$ & 56 \\
\hline
\end{tabular}

a Exposure was expressed in logged concentrations.

b Estimation was based on mixed-effects models.

c $(1.16-0.25) \times 100 / 1.16=78 \%$.

Table 3. Prevalence of sensitization among categories of exposure to inhalable dust, exposure to wheat allergens, industrial sector, and atopy.

\begin{tabular}{|c|c|c|}
\hline Category & $\begin{array}{l}\text { Workers } \\
(\mathrm{N})\end{array}$ & $\begin{array}{c}\text { Sensitization } \\
(\%)\end{array}$ \\
\hline \multicolumn{3}{|l|}{ Exposure to inhalable dust } \\
\hline $0.01-0.59 \mathrm{mg} / \mathrm{m}^{3}$ & 54 & 18.5 \\
\hline $0.59-1.14 \mathrm{mg} / \mathrm{m}^{3}$ & 54 & 33.3 \\
\hline $1.14-2.06 \mathrm{mg} / \mathrm{m}^{3}$ & 54 & 29.6 \\
\hline $2.06-4.70 \mathrm{mg} / \mathrm{m}^{3}$ & 54 & 27.7 \\
\hline $4.70-100.00 \mathrm{mg} / \mathrm{m}^{3}$ & 54 & 20.4 \\
\hline \multicolumn{3}{|l|}{ Exposure to wheat allergens } \\
\hline $0.03-0.34 \mu \mathrm{g} \mathrm{EQ} / \mathrm{m}^{3}$ & 54 & 10.6 \\
\hline $0.34-4.84 \mu \mathrm{g} \mathrm{EQ} / \mathrm{m}^{3}$ & 54 & 25.5 \\
\hline $4.84-15.18 \mu \mathrm{g} \mathrm{EQ} / \mathrm{m}^{3}$ & 54 & 34.0 \\
\hline $15.18-47.39 \mu \mathrm{g} \mathrm{EQ} / \mathrm{m}^{3}$ & 54 & 29.8 \\
\hline $47.39-400 \mu \mathrm{g} \mathrm{EQ} / \mathrm{m}^{3}$ & 54 & 27.1 \\
\hline \multicolumn{3}{|l|}{ Atopy } \\
\hline No & 193 & 16.1 \\
\hline Yes & 77 & 50.6 \\
\hline \multicolumn{3}{|l|}{ Sector } \\
\hline Traditional bakeries & 70 & 37.1 \\
\hline Industrialized bakeries & 72 & 34.7 \\
\hline Bakery-ingredient industry & 55 & 16.4 \\
\hline Flour mills & 73 & 13.7 \\
\hline \multicolumn{3}{|l|}{ Sector \& atopy } \\
\hline \multicolumn{3}{|l|}{ Traditional bakeries } \\
\hline No & 42 & 19.0 \\
\hline Yes & 28 & 64.3 \\
\hline \multicolumn{3}{|l|}{ Industrialized bakeries } \\
\hline No & 52 & 26.9 \\
\hline Yes & 20 & 55.0 \\
\hline \multicolumn{3}{|l|}{ Bakery-ingredient industry } \\
\hline No & 45 & 8.9 \\
\hline Yes & 10 & 50.3 \\
\hline \multicolumn{3}{|l|}{ Flour mills } \\
\hline No & 54 & 9.3 \\
\hline Yes & 19 & 26.3 \\
\hline Total & 270 & 25.9 \\
\hline
\end{tabular}

$2.72 \mathrm{mg} / \mathrm{m}^{3}$ and $9.41 \mu \mathrm{g} \mathrm{EQ} / \mathrm{m}^{3}$, respectively) while the mean exposure level was the lowest, both to inhalable dust and wheat allergens, in the industrialized bakeries (geometric means $1.03 \mathrm{mg} / \mathrm{m}^{3}$ and $2.14 \mu \mathrm{g} \mathrm{EQ} / \mathrm{m}^{3}$, respectively).

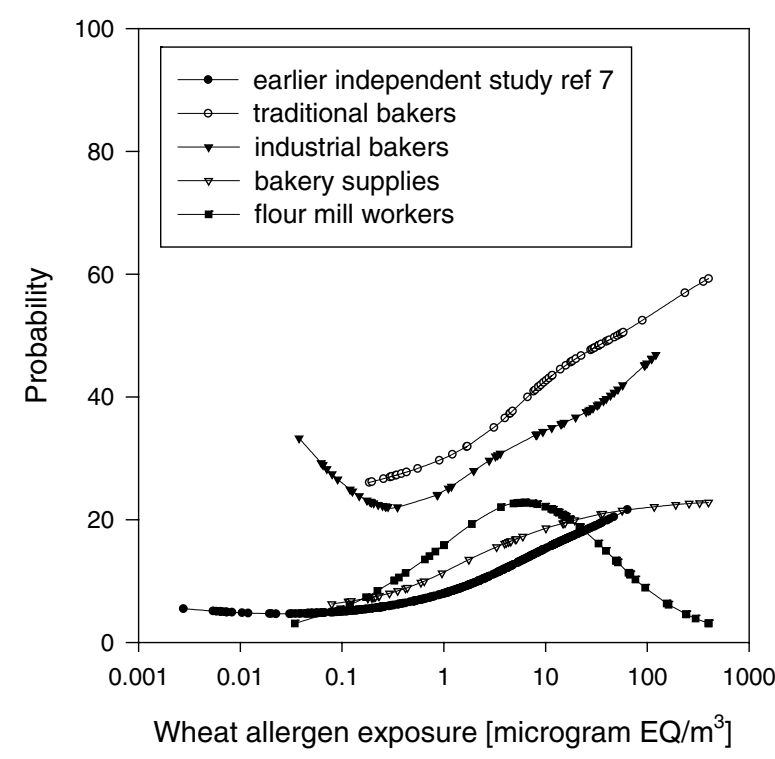

Figure 1. Probability wheat sensitization (Probability) as a function of exposure to inhalable dust by sector of industry, based on actual measured wheat allergens $\left(\mathrm{mgEQ} / \mathrm{m}^{3}\right)$ on a log scale, together with the relationship as published in an independent study (7).

Table 2 presents the variance components of exposure for the models with or without the exposure determinants. When sector, job, and task were accounted for, the variance between the workers was reduced, as expected, by $78 \%$ for inhalable dust and by $56 \%$ for wheat allergens.

\section{Modeling exposure-response relationships}

Table 3 presents the prevalence of sensitization among the various categories of exposure (quartiles), sector of industry, and atopic status. The results of a generalized additive model stratified by sector of industry are presented in figure 1, together with the results from an earlier-published independent study among traditional and industrial bakers (7). The results suggest almost linear relationships for three sectors of industry and an almost quadratic relationship for one sector of industry, with different intercepts for each industry. We then fit a semiparametric generalized additive model to discover the 
appropriate shape of the relationship between sensitization and measured exposure using all the data, and the results of this model for exposure to dust and wheat allergens are given in table 4 . The effect of exposure using a smoothing spline was at least borderline significant for inhalable dust and wheat allergens $(\mathrm{P}=0.0462$ and $\mathrm{P}=0.0941$, respectively) (table 4 ). The relationship between log exposure and sensitization seemed to be quadratic from the scatter-plot of logged exposure and the partial prediction by the smoother. Consequently, we applied a parametric model (ie, a generalized linear model with binominal distribution and logit link), in which the dependent variable was the logit of sensitization and the independent variables were atopy, sector of industry, and the linear and quadratic terms of log exposure.

Table 5 shows the results of the quadratic logistic regression model. Figure 2 depicts the quadratic relationship between exposure and the probability of sensitizing in terms of the different sectors among atopic and nonatopic persons.

The probability of sensitizing increased with greater exposure until it reached $\sim 2.7 \mathrm{mg} / \mathrm{m}^{3}$ for inhalable dust and $\sim 25.7 \mu \mathrm{gEQ} / \mathrm{m}^{3}$ for wheat allergens (figure 2). It later decreased, possibly indicating either a healthy worker effect or development of tolerance. Likewise, the odds ratios for the logged concentrations were at least borderline significant, $1.41(\mathrm{P}=0.0329)$ for inhalable dust and $1.31(\mathrm{P}=0.0142)$ for wheat allergens (table 5). For the squared logged concentrations, the risks were at least borderline significant, $0.84(\mathrm{P}=0.0087)$ for inhalable dust and $0.96(\mathrm{P}=0.1539)$ for wheat allergens.

Table 4. Effects of exposure to inhalable dust $\left(\mathrm{mg} / \mathrm{m}^{3}\right)$ and wheat allergens $\left(\mu \mathrm{g} E / \mathrm{m}^{3}\right)$, industrial sector, and atopy on sensitization, according to a semi-parametric generalized additive model with a smoothing spline. $[\mathrm{df}=$ degrees of freedom, NS= not significant $(P>0.10)$, SE $=$ standard error]

\begin{tabular}{|c|c|c|c|c|c|c|}
\hline & \multicolumn{3}{|c|}{ Inhalable dust } & \multicolumn{3}{|c|}{ Wheat allergens } \\
\hline & $\begin{array}{l}\text { Esti- } \\
\text { mate }\end{array}$ & SE & $\begin{array}{l}\text { P-value } \\
\text { value }\end{array}$ & $\begin{array}{l}\text { Esti- } \\
\text { mate }\end{array}$ & SE & $\begin{array}{c}\mathrm{P}- \\
\text { value }\end{array}$ \\
\hline \multicolumn{7}{|c|}{ Regression model (parametric part) } \\
\hline Intercept & -2.62 & 0.18 & $<0.0001$ & -2.86 & 0.23 & $<0.0001$ \\
\hline Traditional bakeries & 1.22 & 0.34 & 0.0004 & 1.25 & 0.39 & 0.0015 \\
\hline Industrialized bakeries & 1.45 & 0.38 & 0.0002 & 1.48 & 0.36 & $<0.0001$ \\
\hline $\begin{array}{l}\text { Bakery-ingredient } \\
\text { industry }\end{array}$ & 0.56 & 0.54 & NS & 0.71 & 0.53 & NS \\
\hline Flour mills ${ }^{a}$ & - & . & . & - & . & \\
\hline Atopy & 1.75 & 0.33 & $<0.0001$ & 1.69 & 0.36 & $<0.0001$ \\
\hline Linear log concentration ${ }^{b}$ & 0.11 & 0.17 & NS & 0.15 & 0.09 & 0.0824 \\
\hline \multicolumn{7}{|c|}{ Smoothing model (nonparametric part) } \\
\hline Spline log concenctration & $\mathrm{df} \mathrm{c}=\sim 2$ & & 0.0462 & $\mathrm{df}=\sim 2$ & & 0.0941 \\
\hline
\end{tabular}

Table 5. Effects of exposure to inhalable dust $\left(\mathrm{mg} / \mathrm{m}^{3}\right)$ and wheat allergens $\left(\mu \mathrm{g} E \mathrm{Q} / \mathrm{m}^{3}\right)$ and atopy on sensitization, according to a quadratic logistic regression model ( $k=270$ ) based on three types of exposure (industrial sector). [Risk = risk exponent (estimate), VWE = variant-weighted estimator, $95 \% \mathrm{LRCl}=95 \%$ likelihood ratio confidence interval]

\begin{tabular}{|c|c|c|c|c|c|c|}
\hline & \multicolumn{3}{|c|}{ Inhalable dust } & \multicolumn{3}{|c|}{ Wheat allergens } \\
\hline & Risk $^{a}$ & $95 \% \mathrm{LRCl}$ & P-value & Risk & $95 \% \mathrm{LRCl}$ & P-value \\
\hline \multicolumn{7}{|l|}{ Measured exposure } \\
\hline Log concentration a & 1.41 & $1.03-2.01$ & 0.0329 & 1.31 & $1.05-1.67$ & 0.0142 \\
\hline Log concentration^2 b & 0.84 & $0.72-0.96$ & 0.0087 & 0.96 & $0.90-1.02$ & 0.1539 \\
\hline Atopy & 6.12 & $3.26-11.79$ & $<0.0001$ & 5.49 & $2.87-10.75$ & $<0.0001$ \\
\hline \multicolumn{7}{|l|}{ Industrial sector } \\
\hline Traditional bakeries & 3.28 & $1.36-8.34$ & & 3.46 & $1.42-8.86$ & \\
\hline Industrialized bakeries & 4.40 & $1.80-11.54$ & & 4.57 & $1.85-12.06$ & \\
\hline Bakery-ingredient industry & 1.78 & $0.61-5.28$ & & 2.00 & $0.68-5.84$ & \\
\hline Flour mills ${ }^{c}$ & 1.00 &.. & 0.0049 & 1.00 & .. & 0.0040 \\
\hline \multicolumn{7}{|c|}{ Estimated exposure according to sector, job title and tasks } \\
\hline Log concentration $^{\text {a }}$ & 1.24 & $0.83-1.98$ & 0.33 & 1.50 & $1.10-2.18$ & 0.0185 \\
\hline Log concentration^ $2^{b}$ & 0.62 & $0.43-0.83$ & 0.0039 & 0.87 & $0.79-0.95$ & 0.0037 \\
\hline Atopy & 5.90 & $3.23-11.00$ & $<0.0001$ & 5.90 & $3.23-10.99$ & $<0.0001$ \\
\hline \multicolumn{7}{|c|}{ VWE exposure (a weighted average of measured exposure and estimated exposure) } \\
\hline Log concentration a & 1.44 & $1.01-2.15$ & 0.0467 & 1.42 & $1.09-1.89$ & 0.0074 \\
\hline Log concentration^ ${ }^{b}$ & 0.77 & $0.60-0.93$ & 0.0042 & 0.93 & $0.85-1.00$ & 0.0555 \\
\hline Atopy & 6.19 & $3.29-11.95$ & $<0.0001$ & 5.56 & $2.91-10.91$ & $<0.0001$ \\
\hline \multicolumn{7}{|l|}{ Sector } \\
\hline Traditional bakeries & 2.99 & $1.24-7.62$ & & 3.31 & $1.37-8.46$ & \\
\hline Industrialized bakeries & 4.23 & $1.72-11.11$ & & 4.54 & $1.84-11.98$ & \\
\hline Bakery-ingredient industry & 1.67 & $0.56-4.92$ & & 1.90 & $0.65-5.58$ & \\
\hline Flour mills ${ }^{c}$ & 1.00 & .. & 0.0074 & 1.00 & .. & 0.0044 \\
\hline
\end{tabular}

a Log concentration = linear term of log-transformed concentration.

${ }^{\mathrm{b}}$ Log concentration^2 = quadratic term of log-concentration.

c Reference category. 
a) Nonatopic workers
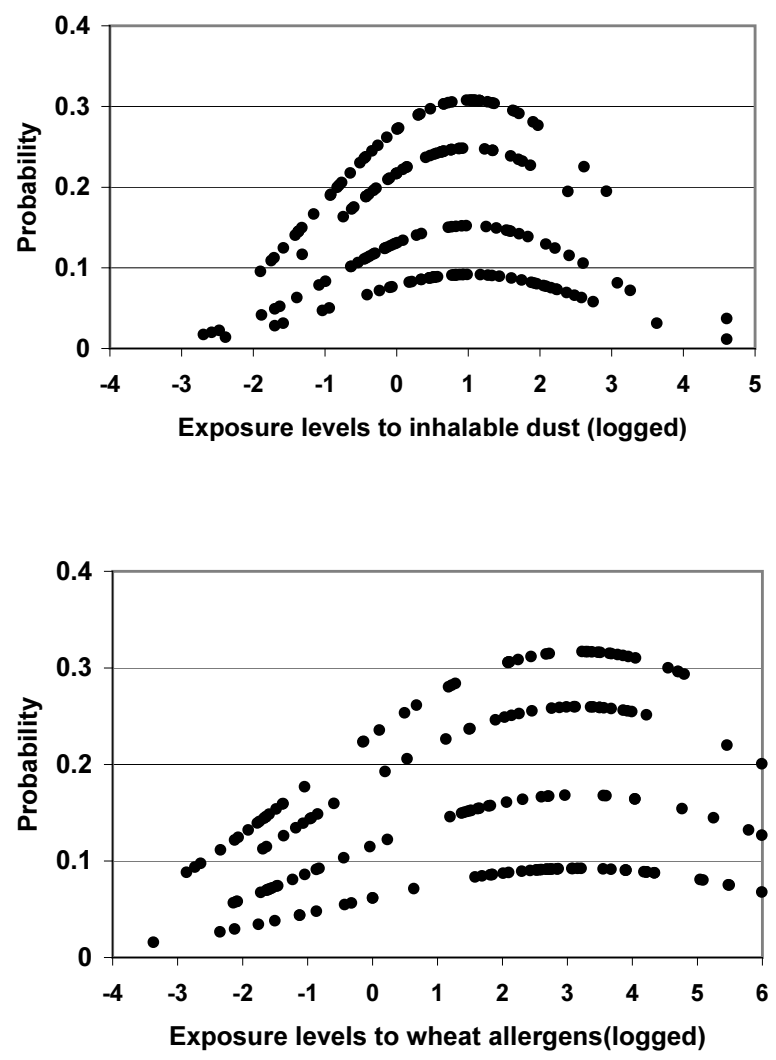

b) Atopic workers
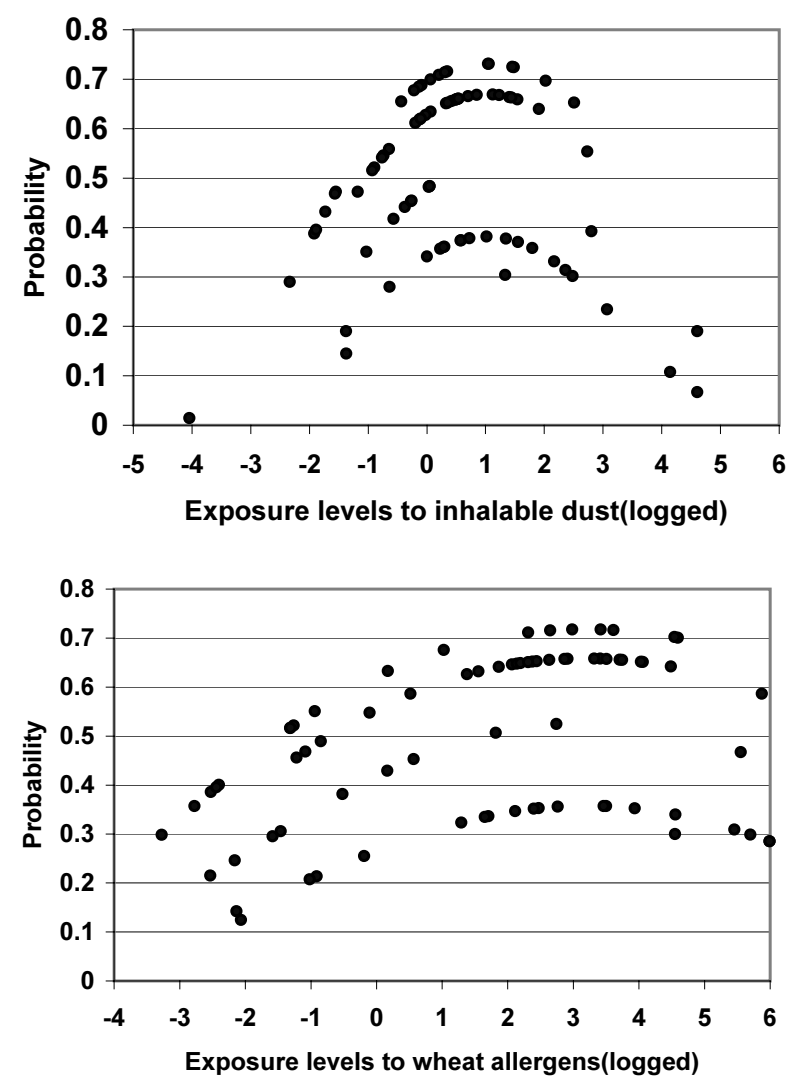

Figure 2. Probability for sensitization (Probability) as a function of exposure to inhalable dust, based on actual measured exposure (logged mg/ $\left.\mathrm{m}^{3}\right)$ and wheat allergens (logged $\left.\mu \mathrm{gEQ} / \mathrm{m}^{3}\right)$ among nonatopic $(\mathrm{N}=193)$ and atopic $(\mathrm{N}=77)$ workers in industrialized bakeries, traditional bakeries, the bakery-ingredient industry, and flour mills (from top to bottom).

Atopy was a highly significant risk factor for sensitization, with a risk of $\sim 6(\mathrm{P}<0.0001)$ in models with both exposures (6.12 and 5.49 for inhalable dust and wheat allergens, respectively). Overall, the probability for sensitization was much higher among the atopic workers when compared with the nonatopic ones. As for the sectors, the risks for the industrialized bakeries were about 4.5 times higher than for both the flour mills and the bakery-ingredient industry for both exposures (figure 2).

There were no significant differences in the risks between traditional and industrialized bakeries or between the bakery-ingredient industry and flour mills.

The risks based on estimated exposures according to sector, job title, and tasks (table 5) did not markedly differ. Table 5 also lists the risks based on exposure according to the variance-weighted estimator, which is a weighted average of the actual exposure and the exposure estimator according to the three covariates of sector of industry, job title, and tasks. The point risk estimators were similar to those based on measured exposure, but they were more accurate. They had almost the same precision and, in exposure to wheat allergens, the quadratic term which was not significant in model a $(\mathrm{P}=0.1539)$ turned out to be much more significant in model $\mathrm{d}(\mathrm{P}=0.0555)$.
We assumed that for each industrial sector the exposure-response relationship was the same. When modeling the exposure-response relationships separately for each sector, we found evidence of a positive linear relationship in all sectors up to an exposure level of around $2.7 \mathrm{mg} / \mathrm{m}^{3}$ for inhalable dust or $25 \mu \mathrm{g} E Q / \mathrm{m}^{3}$ for wheat allergens. Only in the group of flourmill workers did the risk significantly decrease with increasing exposure. The quadratic relationship for the whole population as a result seems strongly driven by data from the flour mills.

\section{Discussion}

The aims of our study were to assess exposure to inhalable dust and wheat allergens among bakers within different sectors and jobs in the baking industry and to evaluate the shape of the relationship with specific sensitization for risk assessment purposes.

\section{Exposure assessment}

Our study cohort was composed of bakers from four industrial sectors, two of which have hardly been studied 
earlier, namely, flour mills and the bakery-ingredient industry. These two sectors were found to have higher significant exposure to both inhalable dust and wheat allergens $(\mathrm{P}<0.001)$ when compared with traditional and industrialized bakeries. Certain jobs, particularly weighing, filling of bags, and "dumping of additives" in the bakery-ingredient industry, contributed to high levels of exposure. We found that grouping by sector of industry and job title explained the differences in exposure to a great extent, given the relatively low exposure variance between workers within a given job category (14). Accounting for tasks resulted in a lower variance between workers and a better fit of the model that associated exposure with its determinants. Our estimated exposures based on grouping strategy by sector of industry and job title were found to be more precise than the individually measured ones. Moreover, the estimated exposure values accounting also for the performed tasks were more valid and more informative for exposure to both inhalable dust and wheat allergens.

Our study did not involve a complete repeated-measurement design. However, the number of repeats $(\approx 20 \%)$ was large enough to give an impression of the day-to-day variability in exposure and was larger than the $10 \%$ often used as a ballpark figure in reliability studies.

\section{Exposure-response relationship}

We studied the shape of the exposure sensitization relationship since there are too few available epidemiologic data on quantitative exposure-response investigations among bakers for risk assessment purposes. The studies in which a monotonic exposure-response relationship was tested had two main disadvantages (15). First, they imposed an a priori choice of cut-off. This approach may result in bias and even raise concern that investigators may select cutoff values that produce a desired result. Second, they made a restrictive assumption of a parametric model of linear shape on the logit scale and applied a linear logistic model. This restrictive assumption was not tested even though the conclusions from these tests depended on their validity. Only one study (7) considered the shape of the relationship using a flexible GAM method without the aforementioned restrictive assumption. The results from our present study and the previous one are strikingly similar. Any GAM model has the disadvantage that, even if it successfully fits the data, it is difficult to obtain estimates of the variability of the parameters or risk factors in order to assess their significances (nonrobustnessnonstability). Therefore, parametric models are preferable over nonparametric ones due to the inferential statistics. We used smoothing as an intermediate step, as an exploratory tool, leading to the desired parametric model. The smoothing analysis showed that the nonlinear relationship can best be approximated by a quadratic one. Consequently, we could assume that the parametric form of the model was a quadratic logistic regression.

We used two exposure assessment approaches, based on either actual exposure measurements or on estimated exposures. Both approaches showed that nonlinear models fit the data best. In this case, we concluded that a quadratic dose-response relationship between exposure to inhalable dust and wheat allergens and sensitization $(\mathrm{P}<0.05$ in comparison with a model without $\mathrm{ex}$ posure terms) gave the best results, although we recognize that other families of untested models may yield a reasonable description of the data as well. Based on actual measured exposure levels, the relationship was found to be monotonic up to a value of $\sim 2.7 \mu \mathrm{g} / \mathrm{m}^{3}$ for inhalable dust and $\sim 25.7 \mu \mathrm{gEQ} / \mathrm{m}^{3}$ for wheat allergens, namely, the higher the exposure the higher the risk. The decline at higher exposures may indicate some kind of tolerance in a specific group of workers, as was suggested to play a role in the exposure of children to domestic allergens $(3,16)$, or a healthy worker effect $(7)$. The latter might be accounted for to some extent by comparing models with present and cumulative or past exposure. However, earlier analyses did not show large improvements and changes in the shape of the exposure-response relationship (7). Longitudinal data are required to explore this in a correct manner. The phenomenon of the flattening of the exposure response, especially the underlying (biological) mechanisms, requires further exploration. However, the heterogeneity in the shape of the exposure-response relationships between the four industries seems to argue against the development of tolerance.

Atopy was found to be a significant modifier in our exposure-response relationship. It is a known risk factor for sensitization $(7,11)$, and the atopic workers had a sixfold higher risk than the nonatopic ones when the exposure level and the sector of industry were accounted for. It was found to be a weaker modifier (a factor of 2 in prevalence ratio) in the Heederik \& Houba study (7), perhaps due to their lower exposure levels or modeling procedure. The industry sector was found to be a significant factor in the exposure-response relationship for both inhalable dust and wheat allergens. Workers in the industrialized bakeries had a four times higher risk of becoming sensitized at the same exposure level as workers in the flour mills and a twice as high risk as workers in the bakery-ingredient industry. Therefore, the sector of industry may serve as a proxy for the kind of dust mixture to which workers are exposed, as well as for the local environment (eg, temperature, degree of use of ventilation devices) or may represent individual characteristics [other than age, gender, or cigarette 
smoking, such as atopy (17)], which contribute to the differences between industries. The difference in the prevalence in atopy between the industries seems to be a key explanatory variable. A remarkable difference in the prevalence of atopy among the four industrial sectors was observed. This difference may point to a strong bias (healthy worker effect), but the exact reason for the difference in atopy prevalence between industries remains obscure.

We have assumed that the shape of the relationship between sensitization and exposure is the same within each industry, but this difference can be questioned. However, regardless of the assumption about the shape of the exposure-response curve, the curve is monotonically increasing, up to intermediate exposure levels. Only at very high exposure levels does the curve flatten or decrease. However, one should be aware that such high levels are not encountered by a substantial number of workers and that they do not occur regularly. Especially for risk assessment purposes, this part of the curve, at high exposure levels, is of less relevance.

In the combined model for all the industries, we observed differences in the probability for sensitization between the sectors of industry at the same exposure levels. This finding seemed to corroborate the atopy prevalence in each subpopulation, and it makes sense, since atopy is a strong modifier, and it considerably determines the sensitization risk with respect to work-related allergens in addition to the exposure.

Previous studies involving linear exposure-response relationships found that there was attenuation when individual exposure data were used instead of exposuregroup means, either obtained directly by grouping or by using statistical models $(14,15,18)$. This finding is in agreement with statistical theory that shows that the performance of individual exposure estimates in exposureresponse studies is sensitive to the effect of day-to-day variability. In our study, quadratic logistic regression with the estimated exposure instead of the actual measured value led to almost the same point estimators of the risk factors. However, the precision of the estimated exposure response relationship differed and was better when modeled exposure was used in the esposureresponse analysis. As in our previous study (19), the random within-worker variability of exposure was highly reduced when tasks that varied from day to day were accounted for. Based on actual measured exposure, the risk estimators for wheat allergens were found to be marginally attenuated in comparison with those estimated according to three exposure determinants. The new four-stage approach for assessing exposure combines actual and estimated exposure to avoid bias in both the point and range estimation of the risk for an illness. The idea of a combined estimate was offered earlier (13), but it was modified by us and showed the most precise results in the expousre-response models.

\section{Implications of this study for an occupational health standard}

The development of an exposure-response curve based on human health effects is important for promulgating occupational standards (20). However, in previous studies involving linear exposure-response relationships, the use of individual exposure data instead of exposuregroup means was associated with attenuation. Our approach tried to overcome this problem, and therefore our conclusions seem to be more valid. Our curves do not suggest a true zero response (= no probability for sensitization), known as the "no observed effect level" (NOEL) in toxicology. This result is in line with earlier findings (7) - albeit very few studies have thus far attempted to evaluate the shape of the relationship between wheat exposure and health outcomes. Therefore, a true threshold dose level (ie, the dose with which a zero response is associated) cannot be defined; instead, only a dose associated with a preset increase in risk (benchmarking) can be calculated.

\section{Acknowledgments}

We thank Professor L Freedman from the Bar Ilan University, Israel, for his statistical assistance with respect to the variant-weighted estimator.

\section{References}

1. American Conference of Governmental Industrial Hygienists. In documentation of the threshold limit values. Cincinnati $(\mathrm{OH})$ : American Conference of Governmental Industrial Hygienists; 1980. p 374-5.

2. American Conference of Governmental Industrial Hygienists. In documentation on flour dust. Cincinnati: $(\mathrm{OH})$ : American Conference of Governmental Industrial Hygienists; 1999.

3. Heederik D, Thorne PS, Doekes G. Health-based exposure occupational exposure limits for high molecular weight sensitizers: how long is the road we must travel? Ann Occup Hyg 2002;46:175-85.

4. Tikkainen U, Louhelainen K, Nordman H. The Nordic Expert Group for Criteria Documentation of Health Risks from Chemicals, 120:Flour dust. Solna: Arbetslivsinstitutet; 1996. Arbete Och Hälsa 27.

5. Brisman J. The Nordic Expert Group for Criteria Documentation of Health Risks from Chemicals, 111: industrial enzymes. Solna: Arbetslivsinstitutet; 1994. Arbete Och Hälsa, 28.

6. Cullinan P, Lowson D, Nieuwenhuijsen MJ, Sandiford C, Tee $\mathrm{RD}$, Venables KM, et al. Work related symptoms, sensitisation, and estimated exposure in workers not previously exposed to flour. Occup Environ Med 1994;51:579-83.

7. Heederik D, Houba R. An exploratory quantitative risk assessment for high molecular weight sensitization: wheat flour. Ann Occup Hyg 2001;45:175-85. 
8. Houba R, Heederik D, Doekes G, van Run PEM. Exposuresensitization relationship for a-amylase allergens in the baking industry. Am J Respir Crit Care Med 1996;154:130-6.

9. Musk AW, Venables KM, Crook B, Nunn AJ, Hawkins R, Crook GD, et al. Respiratory symptoms, lung function, and sensitisation to flour in a British bakery. Br J Ind Med 1989;46:636-42.

10. Platts-Mills TAE, Vaughan J, Squillace S, Woodfolk JA, Sporik R. Sensitization, asthma and a modified Th2 response in children exposed to cat allergen: a population-based crosssectional study. Lancet 2001;357:752-6.

11. SAS Institute. SAS/STAT user's guide, version 8. Cary (NC): SAS Institute; 2000.

12. SAS Institute. SAS/STAT software: changes and enhancements, release 8.1. Cary (NC): SAS Institute; 2001

13. Seixas NS, Sheppard L. Maximizing accuracy and precision using individual and grouped exposure assessments. Scand J Work Environ Health 1996;22:94-101.

14. Heederik D, Attfield M. Characterization of dust exposure for the study of chronic occupational lung disease-a comparison of different exposure assessment strategies. Am J Epidemiology 2000;151:982-90.

15. Leuraud K, Benichou J. A comparison of several methods to test for the existence of a monotonic dose-response relationship in clinical and epidemiological studies. Stat Med 2001;20:3335-51.

16. Platts-Mills TAE, Perzanowski M, Woodfolk JA, Lundback B. Relevance of early or current pet ownership to the prevalence of allergic disease. Clin Exp Allergy 2002;32:335-8.

17. Cullinan P, Cook A, Nieuwenhuijsen MJ, Sandiford C, Tee $\mathrm{RD}$, Venables KM, et al. Allergen and dust exposure as determinants of work-related symptoms and sensitization in a cohort of flour-exposed workers; a case-control analysis. Ann Occup Hyg 2001;45(2):97-103.

18. Nieuwenhuijsen MJ. Exposure assessment in occupational epidemiology: measuring present exposures with an example of a study of occupational asthma. Int Arch Occup Environ Health 1997;70:295-308.

19. Peretz C, Goren A, Smid T, Kromhout H. Application of mixed effects models for exposure assessment. Ann Occup Hyg 2002;46:69-77.

20. Seeley MR, Tonner-Navarro LE, Beck BD, Deskin R, Feron VJ, Gunnar J, et al. Procedures for health risk assessment in Europe. Regul Toxicol Pharmacol 2001;34:153-69.

Received for publication: 15 May 2003

\section{Appendix I}

\section{Sectors and job titles}

\begin{tabular}{|c|c|c|}
\hline Sector & & Job title \\
\hline \multirow[t]{4}{*}{ Traditional bakeries } & 1 & Bread baker \\
\hline & 2 & Confectioner \\
\hline & 3 & Mixed baker (both bread and confectionery) \\
\hline & 4 & Oven worker \\
\hline \multirow[t]{10}{*}{ Industrialized bakeries } & 5 & Bread baker \\
\hline & 5.1 & Dough maker \\
\hline & 5.2 & Control baker (quality assurance) \\
\hline & 5.3 & Cleaning worker \\
\hline & 6 & Confectioner \\
\hline & 7 & Oven worker \\
\hline & 8 & Slicers, packers and transport workers \\
\hline & 9 & Warehouse worker (additives) \\
\hline & 10 & Production manager \\
\hline & 11 & Maintenance worker \\
\hline \multirow[t]{14}{*}{ Flour mills } & 12 & Wheat (grain handler) \\
\hline & 13 & Operator, all-round \\
\hline & 13.1 & Operator, silo \\
\hline & 13.2 & Operator, flour mill \\
\hline & $13.3 / 13.5$ & Operator, wheat cleaning \\
\hline & 14 & Worker involved in filling of bags \\
\hline & 15 & Manager \\
\hline & 16 & Cleaning worker \\
\hline & 17 & Lorry (truck) driver \\
\hline & 18 & Analyst \\
\hline & 20 & Maintenance worker \\
\hline & 21 & Mixer additives \\
\hline & 22 & Control baker (quality control) \\
\hline & 23 & Warehouse worker (additives, eg, transport) \\
\hline Bakery-ingredient & 24 & Weighing \\
\hline \multirow[t]{9}{*}{ industry } & 25 & Filling of bags \\
\hline & 26 & Dumping of additives \\
\hline & 27 & Operator all round \\
\hline & 28 & Stacking of filled bags \\
\hline & 29 & Warehouse worker (additives, eg, transport) \\
\hline & 30 & Control baker (quality control) \\
\hline & 31 & Office worker \\
\hline & 32 & Operator (almond paste, fats) \\
\hline & 33 & Maintenance worker \\
\hline
\end{tabular}




\section{Appendix II}

\section{Calculating variance-weighted average exposure}

\section{[ $v$ = exposure level on a 1-day basis, subject to high day-to-day variability (within-worker variability); $\chi=$ average exposure level over a period]}

The basis of the calculation is the replacement of $v$ by $\mathrm{E}(x / v)$, written here as $\mu_{x / v}$. In our quadratic logistic model, we replace $v$ and $v^{2}$ by estimates $\mu_{x / v}$ and $\mu_{x^{2} / v}$.

\section{(a) Estimation of $\mu_{x / v}$}

In general: $v=x+\delta$ [ $\delta=$ "measurement error" due to day-to-day variability, independent of $x$, with $\mathrm{E}(\delta)=0]$. This implies that:

$$
x=\alpha+\beta v+\varepsilon(\varepsilon=\text { random error) } \quad \text { (equation } 1)
$$

( $v$ and $x$ have means of $\mu_{v}, \mu_{x}$ and variances of $\sigma_{v}^{2}, \sigma_{x}^{2}$, respectively, and the covariances $\sigma_{x v}^{2}, \delta$ and $\varepsilon$ have zero means and variances of $\sigma_{\delta}^{2}, \sigma_{\varepsilon}^{2}$, respectively), where:

$$
\begin{aligned}
& \beta=\frac{\sigma_{x v}}{\sigma_{v}^{2}}=\frac{\sigma_{x}^{2}}{\sigma_{x}^{2}+\sigma_{\delta}^{2}} \\
& \left.\alpha=\mu_{x}-\beta \mu_{v}=(1-\beta) \mu_{x} \text { (since } \mu_{x}=\mu_{v}\right) .
\end{aligned}
$$

Hence:

$$
\begin{aligned}
& x=(1-\beta) \mu_{x}+\beta v+\varepsilon \\
& \mu_{x / v}=(1-\beta) \mu_{x}+\beta w
\end{aligned}
$$

For the $i$-th worker, $z_{\mathrm{i}}$ is the exposure estimator based on the exposure determinants of worker $i$ (stage 1$), s_{b}^{2}$ and $s_{w}^{2}$ are the estimated variance components of $z_{\mathrm{i}}$, which are the same for all workers (stage 2), $n_{i}$ is the number of repeated measures of worker $i(=1,2,3)$, and $\bar{v}_{i}$ is the mean actual measured exposure for worker $i$, based on one to three repetitions. Then:

$$
\begin{aligned}
& \hat{\mu}_{x_{i}}=z_{\mathrm{i}} ; \hat{\beta}=\lambda_{i}=\frac{s_{b}^{2}}{s_{b}^{2}+s_{w}^{2} / n_{i}} ; \\
& \hat{\mu}_{x_{i} / v_{i}}=\left(1-\lambda_{i}\right) z i+\lambda_{i} \bar{v}_{i} \quad \text { (the variance-weighted extimator (VWE) exposure for the } i \text {-th worker) }
\end{aligned}
$$

(b) Estimation of $\mu_{x^{2} / v}$

In general:

$$
\begin{aligned}
& \mu_{x^{2 / v}}=\sigma_{x / v}^{2}+\left[\mu_{x / v}\right]^{2}=\sigma_{\varepsilon}^{2}+\left[\mu_{x / v}\right]^{2} \\
& \sigma_{x}^{2}=\beta^{2} \sigma_{v}^{2}+\sigma_{\varepsilon}^{2} \Rightarrow \sigma_{\varepsilon}^{2}=\sigma_{x}^{2}-\beta^{2} \sigma_{v}^{2}
\end{aligned}
$$

(from equation 1)

Hence:

$$
\mu_{x^{2} / w}=\sigma_{\varepsilon}^{2}-\beta^{2} \sigma_{v}^{2}+\left[(1-\beta) \mu_{x}+\beta v\right]^{2}
$$

For the $i$-th worker: $\hat{\mu}_{x^{2} / w}=s_{b}^{2}-\lambda_{i}^{2}\left(s_{b}^{2}+s_{w}^{2} / n_{i}\right)+\left[\left(1-\lambda_{i}\right) z_{i}+\lambda_{i} \bar{v}_{i}\right]^{2}$ 